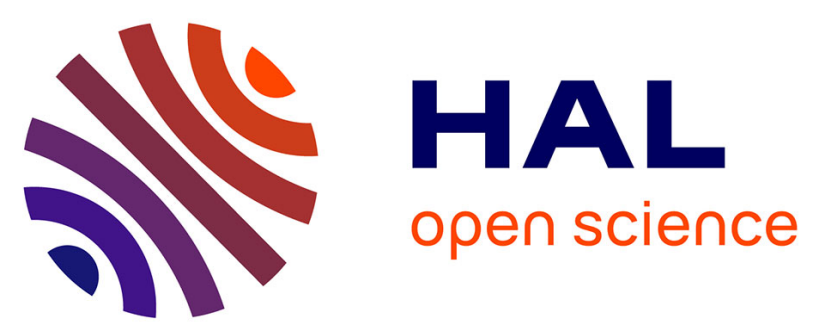

\title{
Study of Polycyclic Aromatic Hydrocarbon formation during acetylene pyrolysis in a jet-stirred-reactor and numerical investigations of residence time distribution using CFD simulations
}

\author{
Tsilla Bensabath, Hubert Monnier, Nathalie Bardin-Monnier, \\ Pierre-Alexandre Glaude
}

\section{To cite this version:}

Tsilla Bensabath, Hubert Monnier, Nathalie Bardin-Monnier, Pierre-Alexandre Glaude. Study of Polycyclic Aromatic Hydrocarbon formation during acetylene pyrolysis in a jet-stirred-reactor and numerical investigations of residence time distribution using CFD simulations. Chemical Engineering Journal, 2019, 377, pp.120244. 10.1016/j.cej.2018.10.181 . hal-02939271

\author{
HAL Id: hal-02939271 \\ https://hal.science/hal-02939271
}

Submitted on 15 Sep 2020

HAL is a multi-disciplinary open access archive for the deposit and dissemination of scientific research documents, whether they are published or not. The documents may come from teaching and research institutions in France or abroad, or from public or private research centers.
L'archive ouverte pluridisciplinaire HAL, est destinée au dépôt et à la diffusion de documents scientifiques de niveau recherche, publiés ou non, émanant des établissements d'enseignement et de recherche français ou étrangers, des laboratoires publics ou privés. 
Study of Polycyclic Aromatic Hydrocarbon formation during acetylene pyrolysis in a jetstirred-reactor and numerical investigations of Residence Time Distribution using CFD simulations

Tsilla Bensabath $^{1,2}$, Hubert Monnier ${ }^{1 *}$, Nathalie Bardin-Monnier ${ }^{2}$, Pierre-Alexandre Glaude $^{2}$

${ }^{1}$ Institut National de Recherche et de Sécurité, 1, rue du Morvan, 54519 Vandœuvre-lès-Nancy, France

${ }^{2}$ Laboratoire Réactions et Génie des Procédés, CNRS, Université de Lorraine, 1, rue Grandville, 54000 Nancy, France

*hubert.monnier@inrs.fr

\section{Highlights}

- Study of PAH formation during pyrolysis in gas carburizing conditions.

- CFD simulations were used to determine Residence Time Distribution.

- Comparison of experimental PAH formation and predictions from a kinetic model.

\section{Graphic illustration for highlights}

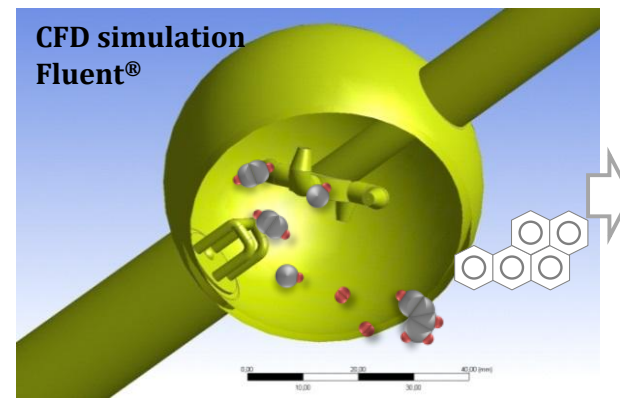

Acetylene pyrolysis jet-stirred-reactor

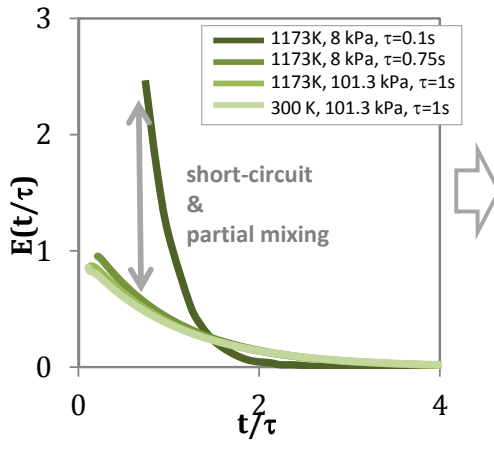

RTD CFD simulations

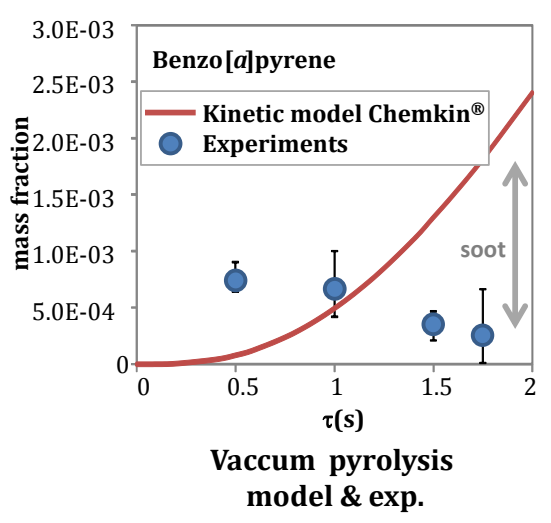




\begin{abstract}
The aim of this study was to understand the formation of PAHs (Polycyclic Aromatic Hydrocarbons) during acetylene pyrolysis. Experiments were carried out with a jet-stirred-reactor in laboratory conditions similar to those used in industrial low-pressure gas carburizing processes $(1173 \mathrm{~K}$ and $8 \mathrm{kPa})$. The influence of residence time was studied. At the outlet from the reaction zone, products of pyrolysis were analyzed by gas chromatography (mass detector). A detailed kinetic model was used to describe $\mathrm{PAH}$ formation and to validate experimental findings. Differences were found between the experiments and the kinetic model. Several explanations are presented such as a lack of mixing within the reactor. To explain why the reactor's hydrodynamic characteristics deviate from the perfectly stirred assumption under several operating conditions, such as low-pressure and high temperature, CFD calculations were performed to determine the Residence Time Distribution (RTD) of the gas phase. This deviation is particularly linked to the pressure in the chamber which was not taken into account when constructing the jet-stirred-reactor over the last fifty years.
\end{abstract}

Keywords: Pyrolysis, PAH, carburizing, jet-stirred-reactor, residence time distribution

\title{
1. Introduction
}

Low-pressure gas carburizing is a heat treatment process used to increase the surface hardness of steel by the addition of carbon atoms. Surface chemical reactions occur between some hydrocarbons and steel parts causing atomic carbon to diffuse within the steel [1,2]. Simultaneously, gas phase pyrolysis occurs. As a result, this process produces by-products, including Polycyclic Aromatic Hydrocarbons (PAH) which may contain carcinogenic substances such as benzo[a]pyrene (BaP) [3]. These by-products condense in cold zones in the reactor, mainly exhaust pipes [4]. During maintenance and cleaning operations, workers may be exposed to these substances through inhalation and skin contact. This study aimed to identify the pathways leading to the formation of 
chemical compounds so as to establish operating conditions which would improve occupational risk prevention when using and maintaining low-pressure gas carburizing furnaces.

Several experimental set-up to increase the comprehensive reaction mechanism in several pyrolysis and combustion with a plug flow reactor or a perfect stirred reactor can be found in the literature. Ghent University (Belgium) studied mechanism for catalyst regeneration from carbon deposits [5] thanks to a transient technique: the Temporal Analysis of Products (TAP) [6-7]. It is often used to investigate the isothermal carbon species gasification process or catalysis reactions and its high time resolution allows formulating the reaction mechanism. The TAP consists of injecting a very small amount of gas (nanomoles per pulse) into a small tubular vacuum fixed bed reactor to be with a perfect stirred reactor assumption. Another experimental pyrolysis apparatus used a pipe with a larger length and inner diameter $[8,9]$ than the TAP uses. The aim is to ensure the plug flow and the isothermal assumption during experiments.

As far as our study of gas pyrolysis is concerned, laboratory experiments were carried out with a jet-stirred-reactor, JSR [10-14]. This reactor was often used for combustion and pyrolysis studies because it can be assumed to be a perfectly stirred reactor [15-19]. To the best of our knowledge, Gil and Mocek, 2012 [14] is the first study which uses the JSR at low pressure. This assumption is important to allow comparison of results from kinetic models to experimental data. The temperature and composition homogeneity in the JSR makes kinetic analyses and simulation easier than in tubular reactors. The simulation of the JSR can easily be implemented with comprehensive detailed kinetic models using softwares as Chemkin ${ }^{\circledR}[20]$.

However, the ideal flow pattern within the continuous JSR may only be valid for certain process conditions. If operating conditions such as temperature, pressure or the compounds used are altered, the hydrodynamic conditions may be modified [21,22]. Thus, experimental data and results obtained from a kinetic model may differ due to an invalid assumption. To ensure the validity of the assumptions made, the numerical residence time distribution (RTD) was determined by computational fluid dynamics simulations (CFD) using Fluent Ansys ${ }^{\circledR}$ software [23-25]. 
The results of this work show how residence time influences the formation of PAH at $1173 \mathrm{~K}$ and 8 $\mathrm{kPa}$ (pyrolysis conditions applied during carburizing processes). Experiments were carried out with the JSR, and CFD simulations were performed to try to identify the potential sources of discrepancies observed between JSR and simulations of a perfectly stirred reactor. Finally, data from a detailed kinetic model were compared to our experimental results [26].

\section{Materials and methods}

\subsection{Jet-stirred-reactor characteristics}

The JSR used in these experiments is composed of a sphere and two pipes (Figure 1). The mediumsized sphere corresponds to the reactor, and is assumed to be perfectly stirred. The JSR was manufactured by Veral (Colombes, France) from quartz so that it can be used at the high temperature required for carburizing $(1173 \mathrm{~K})$. Chemical reactions take place in the sphere, into which gas is injected from four different directions through nozzles positioned as shown in Figures 2 and 3.

To study the carburizing process, a quartz support was made to allow a steel part to be placed in the reactor. Carburizing itself will not be discussed in this article, but the presence or the support can change the reactor's hydrodynamic characteristics. Quartz pipes used to transport acetylene into the sphere located in the middle of the furnace allow avoiding boundary effects. This positioning allows products to be extracted as quickly as possible, thus avoiding chemical reactions in the pipes. To reduce the residence time for chemical species in the pipes and to increase their velocity, acetylene and exhaust products transit through annular spaces. The high surface/volume ratio characteristic of the annular zone allows also the preheating of the reactants up to the reactor temperature to avoid temperature inhomogeneity [27]. 


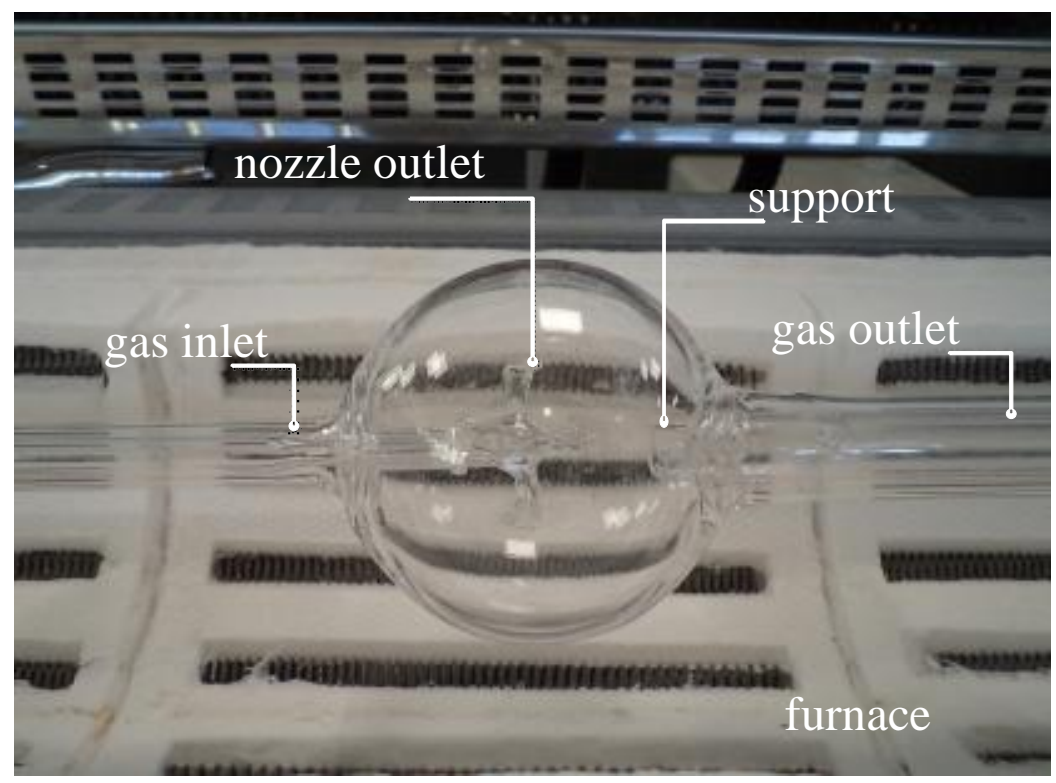

Figure 1: Photograph of the JSR [10] in a furnace - Parts were made of quartz by Veral (Colombes, France).

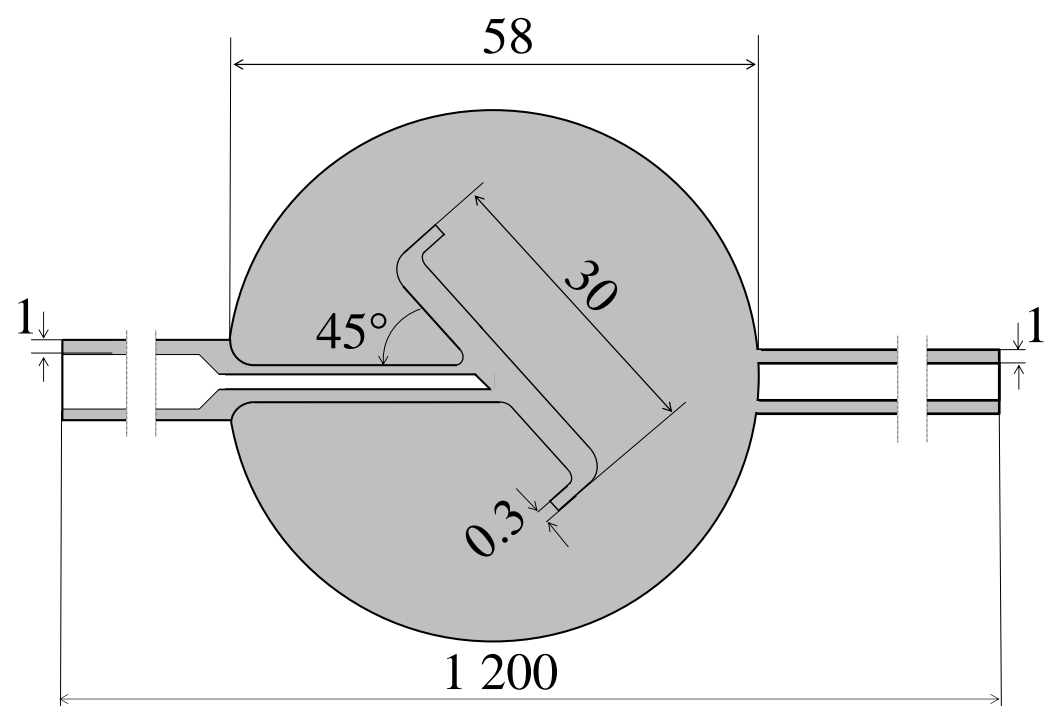

Figure 2: Diagram of the JSR (cross-section) containing a support on which a steel part can be placed for carburizing (dimensions are given in $\mathrm{mm}$ ) $-\mathrm{V}_{\text {sphere }}=102 \mathrm{~mL}, \mathrm{~d}_{\text {nozzle }}=300 \mu \mathrm{m}$,

$$
\mathrm{S}_{\text {nozzle }}=0.07 \mathrm{~mm}^{2}(\text { Table 1) [10] }
$$

Table 1 presents the residence times in each part of the reactor for the different flow rates used. 


\begin{tabular}{|c|c|c|c|c|c|}
\hline \multicolumn{3}{|c|}{ reactor part } & inlet pipe & sphere & outlet pipe \\
\hline \multicolumn{3}{|c|}{ pipe length $(\mathrm{mm})$ and sphere diameter $(\mathrm{mm})$} & 571 & 58 & 571 \\
\hline \multicolumn{3}{|c|}{ thickness of annular spaces (mm) } & 1 & $(-)$ & 1 \\
\hline \multicolumn{3}{|c|}{ gas volume $(\mathrm{mL})$} & 16 & 102 & 20 \\
\hline $\begin{array}{l}\text { acetylene flow rate } \\
\qquad(\mathrm{NmL} / \mathrm{min})\end{array}$ & $\begin{array}{l}\text { acetylene flow rate at } 1173 \mathrm{~K} \text { and } 8 \mathrm{kPa} \\
\qquad\left(\mathrm{x} 10^{3} \mathrm{~mL} / \mathrm{min}\right)\end{array}$ & $\frac{\tau_{\text {sphere }}}{\sum \tau_{i}}$ & \multicolumn{3}{|c|}{$\tau(\mathrm{s})$} \\
\hline 225 & 12 & \multirow{4}{*}{74} & 0.08 & 0.5 & 0.10 \\
\hline 112 & 6.1 & & 0.16 & 1 & 0.19 \\
\hline 75 & 4.1 & & 0.24 & 1.5 & 0.29 \\
\hline 64 & 3.5 & & 0.28 & 1.75 & 0.34 \\
\hline
\end{tabular}

Table 1: Geometric characteristics of the JSR and operating parameters applied

The gas velocity at the outlet from the nozzles must remain below the speed of sound to avoid damage to the quartz walls of the JSR [28]. The mathematical condition with sonic limit depends on $\mathrm{T}$ and $\mathrm{P}$ and is given by Eq. 1 :

$\frac{4}{3} \frac{R_{\text {sphere }}^{3}}{d_{\text {nozzle }}^{2} \tau} \leq c_{\text {sound }}(T, P)$

Using the dimensions of the JSR ( $\mathrm{d}_{\text {nozzle }}$ and $\mathrm{R}_{\text {sphere }}$ ), the speed of sound calculated at $1173 \mathrm{~K}$ and $8 \mathrm{kPa}(646 \mathrm{~m} / \mathrm{s})$ and equation 1 , it was possible to determine the minimum value for the residence time. Its maximum value was fixed because of the large amount of soot and tar generated within the reactor which obstructs the nozzles. Indeed, the conversion rate of acetylene increases with residence time resulting in high PAH concentrations [26]. As a first approximation, the residence time chosen to explain the chemical reaction was that for the sphere alone; the residence time in the two pipes was neglected (Table 1).

The hydrodynamics of the JSR were previously studied by determining the RTD for different regions in the reactor at room temperature, atmospheric pressure and with air [10,22]. Because page 6 
pyrolysis reactions occur at high temperature, low-pressure and without air, it appeared important to investigate the influence of these parameters on flow in the JSR. Therefore, CFD simulations were performed to characterize the reactor's hydrodynamics to confirm the hypothesis of perfect mixing at high temperature and vacuum pressure based on RTD measurements [29-31].

\subsection{CFD simulations}

In this study, the reactor's hydrodynamic behavior was only investigated using CFD simulation [14]. The geometry of the simulated reactor was designed thanks to the reactor used in the laboratory (Figure 3).

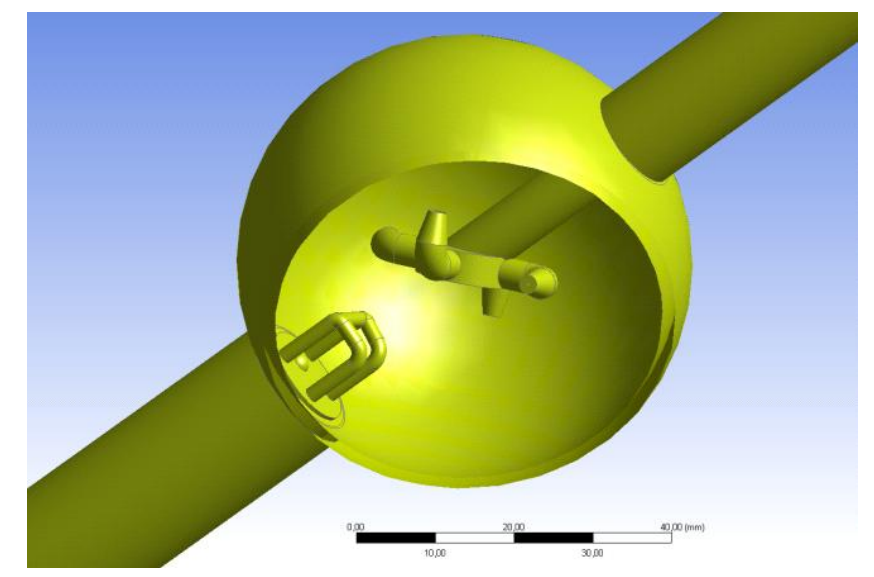

Figure 3: Design of JSR [10] produced by Design Modeler software (Ansys ${ }^{\circledR}$ ) [25]

As the reactor does not have an axis of symmetry, a 3D model of the reactor was simulated using a commercial CFD code. CFD simulations were performed using the Workbench $^{\circledR}$ software package developed by Ansys ${ }^{\circledR}$; Design Modeler, Meshing and Fluent Ansys ${ }^{\circledR}$ were used to perform calculations based on the finite-volume method [14,25,32,33].

The RNG-k- $\varepsilon$ turbulence model was chosen to keep a reasonable computational effort (calculation time) while taking into account the physics of the flow [32]. The RNG-k- $\varepsilon$ model tends indeed to request $10-15 \%$ more calculation time than the standard $\mathrm{k}-\varepsilon$ model, but it allows a better consideration of the turbulent viscosity while the $\mathrm{k}-\varepsilon$ model is more used to treat diffusivity 
phenomena [25]. The RSM model would be the most appropriate by using a coupling between the Reynolds stresses and the mean flow.

Nevertheless, the RNG k- $\varepsilon$ model with "Enhanced Wall Treatment" was used because on the one hand it requires less calculation time than the RSM model (40\%) and the other hand, the order of magnitude of the average value of the non-dimensional wall distance, $\bar{y}^{+}$(for sphere wall and nozzle walls) is below 1 at $8 \mathrm{kPa}-1173 \mathrm{~K}$ with $\mathrm{y}^{+}$values, ranging from $210^{-4}$ to 30 [34]. At $101.3 \mathrm{kPa}$ and $293 \mathrm{~K}, \mathrm{y}^{+}$values are higher than at $8 \mathrm{kPa}-1173 \mathrm{~K}$. However its maximum value stays above 70. If the sub-viscous region is below $100, \mathrm{RNG} \mathrm{k- \varepsilon}$ model can be used between $0<\mathrm{y}^{+}$ $<5$, CFD calculations have to be performed by adding to the RNG k- $\varepsilon$ model the "Enhanced Wall Treatment" and enough cells within the boundary layer on the mesh thanks to the "Inflation program" (Figure 4) [25].

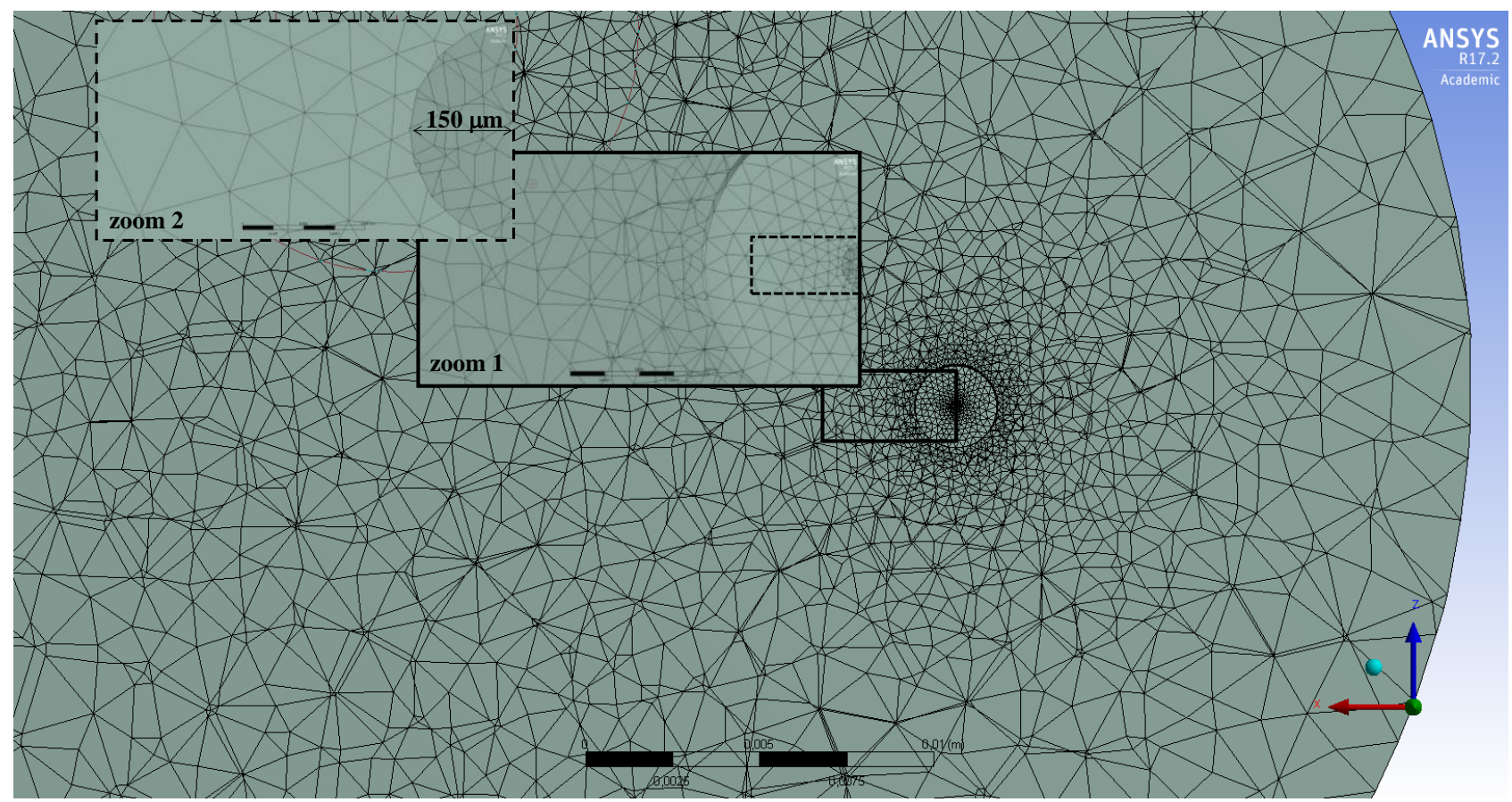

Figure 4: Cross-sectional view of the geometry of the sphere and one nozzle with zoom 1 and zoom 2 to show the gradient of mesh size used "Inflation Program" (Ansys ${ }^{\circledR}$ ) to take into account the subviscous region $\left(\bar{y}^{+}<5-y_{\max }^{+}<30\right.$ at $\left.8 \mathrm{kPa}, 1173 \mathrm{~K}\right)$ close to small part like nozzle. 
Simulations were performed for nitrogen at constant density and dynamic viscosity (assuming it to be an incompressible fluid), under isothermal conditions, and with negligible gravity at $8 \mathrm{kPa}$ and 1173 K. Continuity, balance of momentum and conservation of energy equations were used and are listed below [35].

The continuity equation is given by:

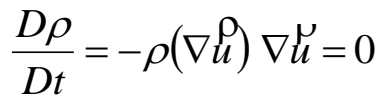

The Navier-Stokes simplified equation was used:

$$
\rho \frac{D \ddot{u}}{D t}=-\nabla P-\rho(\stackrel{\rho}{\rho} \cdot \stackrel{\rho}{\rho}) \mu+\mu \nabla^{2} \stackrel{\rho}{\rho}
$$

To solve these equations, the boundary conditions assume no slip and no heat transfer between the inside and the outside of the reactor at the walls. The temperature was maintained constant on all walls (see $\S 2.3$.). Gas velocity is specified at the entrance to the reactor and the outlet pressure was set to the pressure for the carburizing process $(8 \mathrm{kPa})$. The turbulence intensities at the outlet and inlet boundaries were set to $5 \%$. This low value was chosen because the flow is mainly laminar (the order of magnitude of the Reynolds number in a nozzle at $1173 \mathrm{~K}$ and $8 \mathrm{kPa}$ is below 70 ), but some turbulence zones within pipes or other areas like bends of nozzle may be generated.

The mesh of the reactor volume was composed of $10^{7}$ elements. Three regions were created and connected: the inlet pipe, the sphere with its four nozzles, and the outlet pipe. These regions were modeled by a combination of tetrahedral and hexahedral meshes. The grids for the inlet and outlet pipes were composed of $10^{5}$ hexahedral mesh elements. In the sphere, the structured grid was made of $10^{5}$ tetrahedral mesh elements. A very small mesh size was required close to the nozzle to obtain accurate results, but the mesh had to remain large enough to reduce the number of cells near the wall of the sphere. Therefore, a gradient of mesh size was used (Figures 4 and 5).

In order to reduce the calculation time while respecting the results accuracy, "Automatic Method" and "Patch Conforming Method" were used for the two pipes and sphere, respectively [25]. The "Automatic Method" is a classical technique of meshing used to cylinder shape such as our pipes. 
The "Patch Conforming Meshing" is a technique selected in Meshing software in which boundaries of the faces (solid-fluid and fluid-fluid) are taken into account with a very small tolerance. This method is used to overcome difficulties with small features geometry. In our case, it is important to work with a mesh refinement because the sphere contains elements with several orders of magnitude: outlet diameter of nozzle $(300 \mu \mathrm{m})$, diameter of the sphere $(58 \mathrm{~mm})$, nozzle bend, etc. Otherwise, the "Patch Conforming Meshing" uses "Inflation" to increase the CFD boundary layer resolution: the number of layers was equal to 5 and a growth rate equal to 1.2. The figure 5 shows a cross-sectional view of the geometry of the reactor. It allows showing inside important areas involved with zooms,

- the different meshes used for two pipes and sphere,

- the quality of the grid: fine, coarse adopted,

- $\quad$ the mesh close to boundaries (solid-fluid) and at the junction of pipe-sphere.

Afterwards, to ensure a fine mesh close to the junctions of pipes and sphere, the mass balance was determined for different regions in the reactor at steady state on both sides of the junctions. The mass balance and the residual calculated are lower than $10^{-3} \%$ and $10^{-3}$ respectively. Consequently, to perform CFD calculations the grid chosen is based on technical recommendations of Ansys ${ }^{\circledR}$ [25]. 

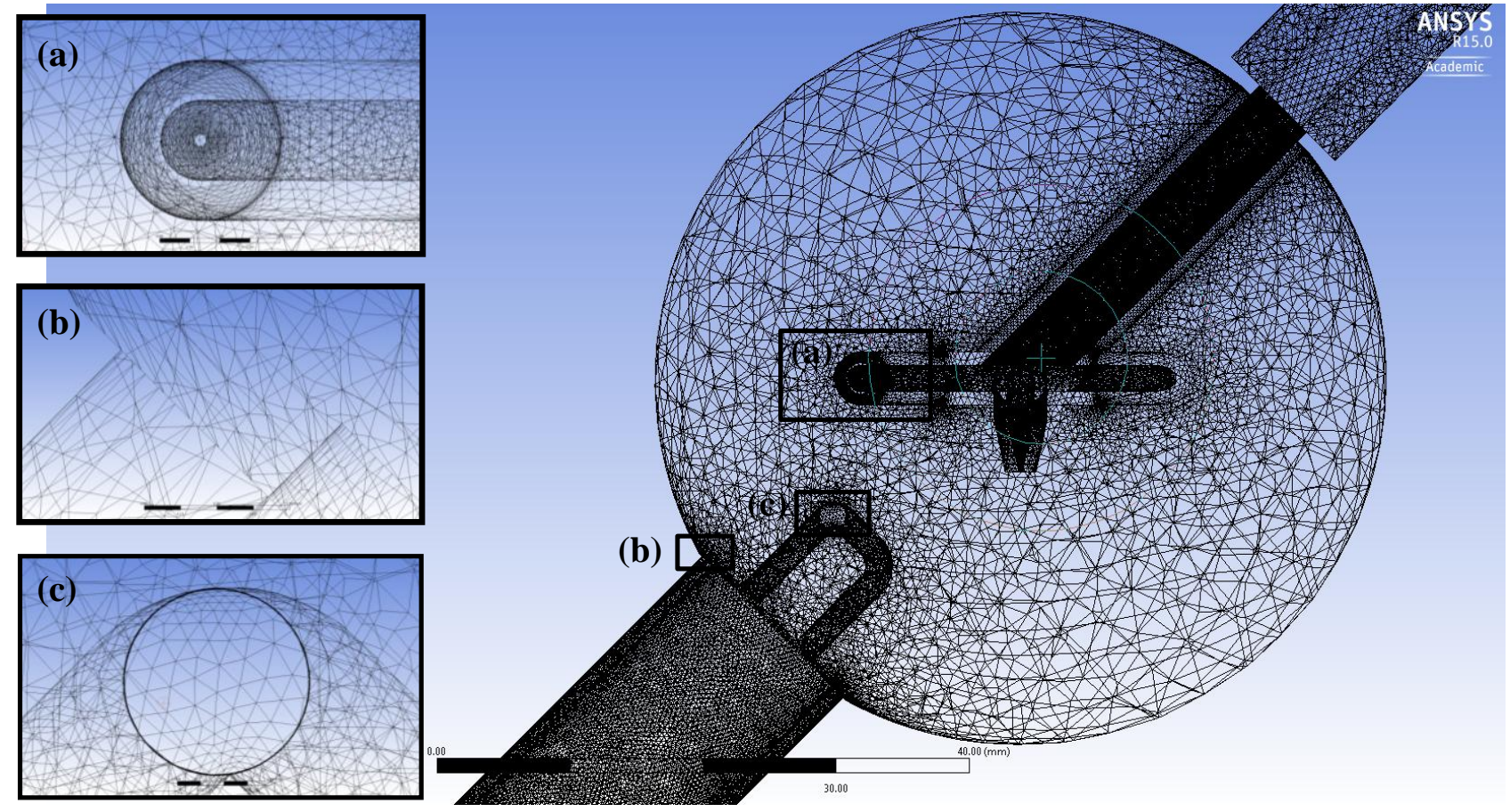

Figure 5: Cross-sectional view of the geometry of the reactor with three zooms of areas involved (a) close to nozzle within sphere, (b) at the junction of pipe-sphere for the gas outlet, (c) around quartz part surrounded by gas.

However, the mesh within the nozzles must be fine enough to improve the accuracy of the CFD calculations. The mass balance may be not sufficiently satisfied close to the four nozzles when the mesh is coarse. The figure 6 represents the grid of one nozzle section with zooms. Calculations for four residence times were performed on the one hand with (a) a fine mesh and the other (b) with a coarse one. For each mesh, a calculation of deviation of the mass balance between the reactor inlet (inlet pipe) and the sum of the outlets of the four nozzles was carried out. The deviation increases with the residence time (Figure 6). However its order of magnitude remains suitable with the fine mesh. Nevertheless, the gap between the mass balance deviations of two meshes is between $120 \%$ and $180 \%$ (Table in figure 6). Therefore fine mesh for four nozzles was used. In other words, around 100 elements were retained (fine mesh - Figure 6a) for the four nozzle sections $\left(0.07 \mathrm{~mm}^{2}\right)$ to achieve a sufficient equilibrium for the mass balance between the inlet of the reactor and the sum of the four outlet nozzles. 


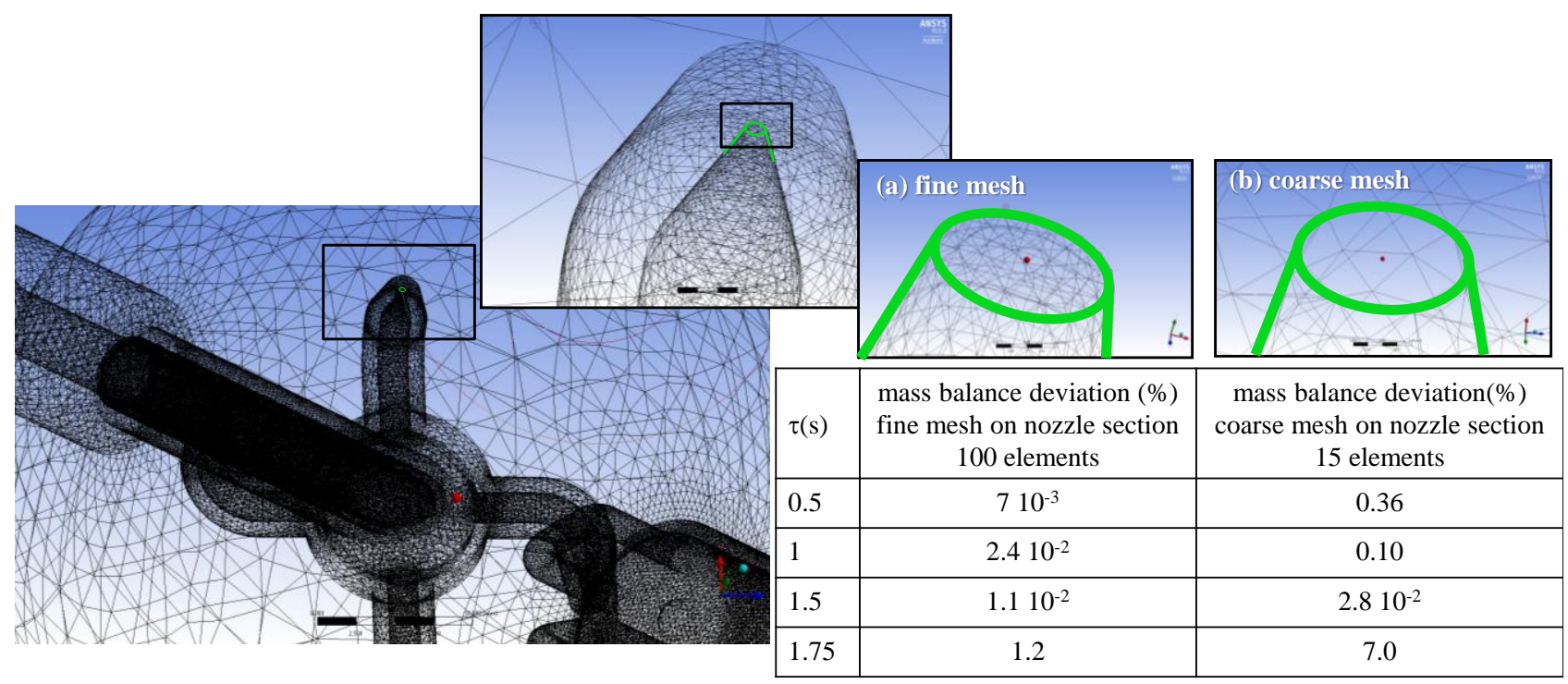

Figure 6: Representation of the grid with zooms of the nozzle outlet with (a) fine and (b) coarse mesh - calculation of deviation of the mass balance between inlet pipe and outlet of four nozzles

\subsubsection{Pulse input signal for RTD calculation}

A pulse tracer was used as the stimulus when performing some RTD calculations. It enters through the inlet to the JSR and the response calculated to determine RTD is based on its concentration in the reactor's exhaust flow. Simulations were carried out in a transient state to determine the RTD. Two gas species were used in the CFD model to predict RTD: a flow of nitrogen and a defined tracer gas which has the same physical and chemical characteristics as nitrogen. The inlet velocity was set to between $0.1 \mathrm{~m} / \mathrm{s}$ and $5 \mathrm{~m} / \mathrm{s}$, depending on the desired residence time; these speeds remained below the sonic limit at the nozzle outlet [10]. To decrease the calculation time and to study the hydrodynamic characteristics of the sphere alone, without pipes, the inlet and outlet pipes were shortened. The modifications to the geometry allow RTD to be determined only for the sphere and its four nozzles. The calculation is performed in three steps:

1. After initializing all parameters, the JSR is filled with nitrogen until it reaches a steady state (mass balance $<0.01 \%$ ). 
2. The calculation is then performed in a transient state following injection of a stimulus of pure tracer gas for $0.05 \mathrm{~s}(<10 \%$ of residence time). The time step is set to $0.01 \mathrm{~s}$. It is over 50 times shorter the residence time in the sphere (50 and 175 for the residence time of 0.5 and $1.75 \mathrm{~s}$ respectively - Table 1). The time step has been chosen according to the theoretical residence time in the sphere.

3. The initial condition corresponds to the final condition from part 1.

4. Finally, the calculation continues in a transient state and with pure nitrogen until $t>5 \tau$, e.g. when the gap between two inlet concentrations is lower than $10^{-3} \%$.

The tracer concentration was monitored at the outlet of the sphere. The RTD is represented by the E curve thanks to the tracer concentration at the outlet as a function of the normalized time, $\mathrm{t} / \tau$ [30].

$$
E(t, \tau)=\frac{C(t / \tau)}{\int_{0}^{+\infty} C(t / \tau) d t}
$$

The CFD residence time, $\tau_{C F D}$ can then be calculated by applying the method of moments [29,30,35]. CFD simulations were compared with the ideal RTD determined using Eq. 5:

$$
E(t, \tau)=\exp \left(-\frac{t}{\tau}\right)
$$

To characterize the deviation from the ideal working, CFD simulations and the ideal RTD curves were compared. The data obtained from the ideal model (Eq. 6) were fitted to the CFD simulation results.

The ideal fitted residence time, $\tau_{\text {ideal } \text { fit }_{\text {f }}}$ was deduced from this fitting. The aim was to compare the difference between the two residence times, as defined by Eq. 6 :

$$
r_{\tau}=\frac{\left|\tau_{C F D}-\tau_{\text {ideal_fit }}\right|}{\bar{\tau}}
$$

Where $\bar{\tau}$ is the arithmetic mean of $\tau_{C F D}$ and $\tau_{\text {ideal } f_{-} \text {fit }}$. 
We also used the method developed by Cholette and Cloutier (1959) [36] to determine mixing efficiencies in a continuous flow system and to assess their performance. The aim of this aspect of the study was to take the effective mixing volume and any possible short-circuits into account. It further characterizes the hydrodynamics of our JSR thanks to Eq. 7:

$\ln \frac{C(t)}{C_{0}}=\ln n-\frac{n}{m} \frac{t}{\tau}$

Where $m$ is the fraction of total reactor volume assumed to be well stirred and $n$ is the fraction of inlet flow which contributes to the perfectly stirred volume. Thus, the deviation from ideal mixing can be characterized by:

$r_{\text {short-circuit }}=1-n$, the fraction of short-circuit,

and

$r_{\text {partial mix. }}=1-m$, the fraction of fluid which is partially mixed.

For all RTD curves, the deviation from the ideal was characterized and discussed with respect to $r_{\tau}$,

$r_{\text {short-circuit }}$ and $r_{\text {partial mix. }}$.

\subsubsection{Step input signal for RTD calculation}

To show the influence of the twin pipes located on either side of the sphere, some CFD simulations were carried out with a pulse trace, which is the preferred method for more complex reactors [31,37]. Initially, the JSR was filled with nitrogen until it reaches a steady state. The velocities $\left(\mathrm{u}_{\mathrm{x}}\right.$, $\mathrm{u}_{\mathrm{y}}, \mathrm{u}_{\mathrm{z}}$ ), pressure, etc. were calculated for all cells in the mesh until the convergence criterion was reached:. The residual sum for each of variables decay to $10^{-4}$. When this criterion was reached, mixing was investigated by introducing a pulse of pure tracer gas. The calculation was then performed in a transient state for $t>5 \tau$.

The time step has been chosen according to the theoretical residence time of the reactor (two pipes and the sphere). It was set to $0.01 \mathrm{~s}$ to achieve an accurate result because of it is over 50 times 
shorter than the residence time of the reactor (which is close to the residence time of the sphere Table 1).

The tracer concentration was monitored at the outlet from the reactor. It changes from 0 to $\mathrm{C}_{0}$ and it can be normalized and expressed as follows:

$$
F(t, \tau)=\frac{C(t)}{C_{0}}
$$

Where $\mathrm{C}(\mathrm{t})$ and $\mathrm{C}_{0}$ are the concentration of tracer and the maximum concentration of tracer measured at the reactor outlet, respectively, and $\mathrm{F}$ is the downstream signal [31].

In order to ensure the perfectly mixed assumption, the expression for the ideal downstream signal is used (Eq.11):

$$
F(t, \tau)=1-\exp \left(-\frac{t}{\tau}\right)
$$

Data from CFD calculations used to determine RTD were fitted to those produced by the ideal model. The aim was to determine the residence time and to compare it to the ideal residence time, $\tau_{\text {ideal }}$ which characterizes perfect mixing, as defined by Eq. 12:

$$
\tau_{\text {ideal }}=\frac{V}{Q}
$$

To calculate it, the overall volume of the reactor, the two annular pipe volumes and the sphere volume (Table 1), is taken into account.

\subsection{Experimental setup}

Acetylene pyrolysis experiments were performed in the experimental setup shown in Figure 7. This setup consists of a gas feeding system, a reaction system, and a product collection system. Lowpressure is achieved by means of a rotary vane pump (Edwards E1M18 Atex3) and controlled thanks to a solenoid control valve (MKS 0248A) and absolute pressure transducers (MKS Baratron $^{\circledR}$ 622B). Gases (acetylene and nitrogen) were contained in gas cylinders (Air Liquide and 
Air Products ${ }^{\circledR}$ ) and flow rates were adjusted using mass flow controllers (Brooks ${ }^{\circledR}$ SLA 5850S). Nitrogen is an inert gas and is used to exclude air and particularly oxygen from the experimental setup to avoid combustion reactions. A single controller is sufficient to cover the full range of acetylene flow rates between $64 \mathrm{NmL} / \mathrm{min}$ and $225 \mathrm{NmL} / \mathrm{min}$ to study the influence of the gas residence time between $1.75 \mathrm{~s}$ and $0.5 \mathrm{~s}$, respectively (Table 1). The reactor was positioned horizontally in a tubular three-zone furnace (Carbolite ${ }^{\circledR}$ HZS 12/600). The sphere was placed in the middle of the furnace. The connections between flexible and rigid stainless steel pipes and the quartz parts were purchased from Swagelok ${ }^{\circledR}$, Neyco ${ }^{\circledR}$ and Oerlikon Leybold Vacuum.

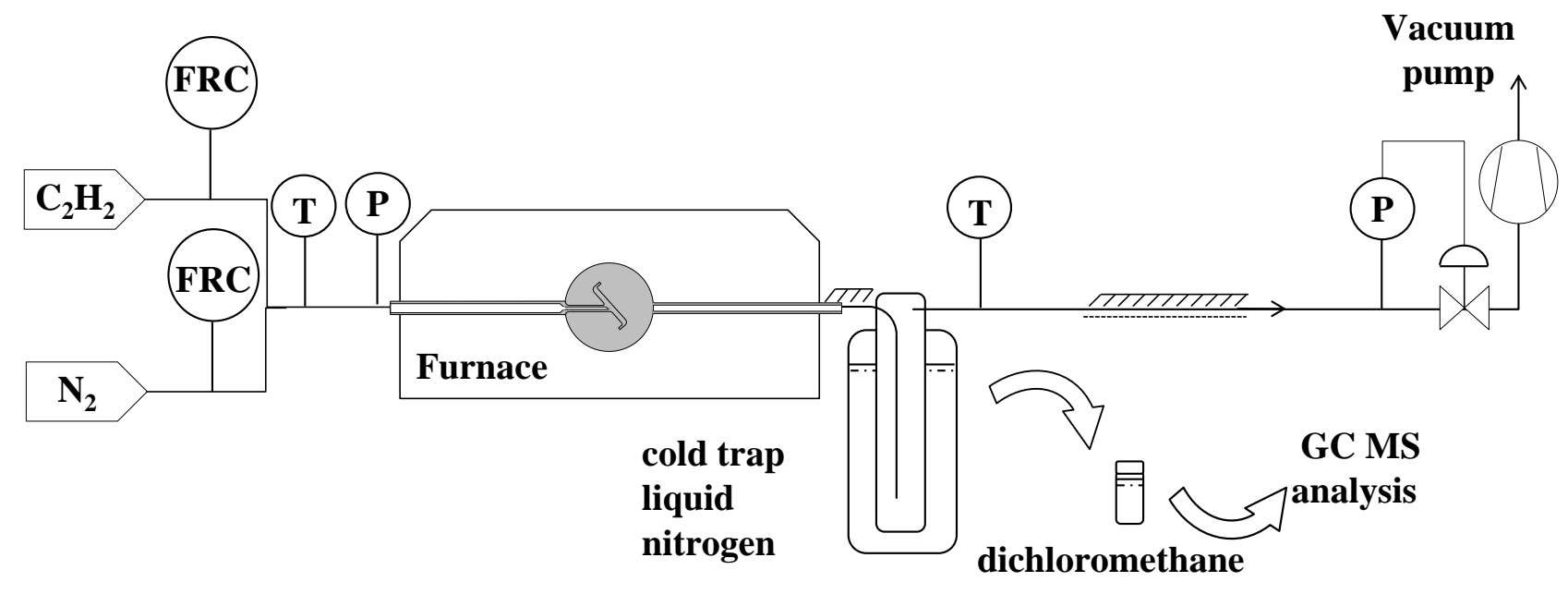

Figure 7: Experimental setup ( - - - - - heating flex; $77 / 7$ insulation; T: temperature sensor; P:

pressure sensor; FRC: mass flow controller)

To analyze PAH formation, all but the lightest species were condensed on the walls of a cold trap (KGW Isotherm) cooled by liquid nitrogen (Linde group). The stream at the outlet from the trap was analyzed by on-line gas chromatography (not shown in Figure 7). Results showed that the amount of product exiting the trap is negligible, except for the lightest products such as hydrogen and methane, which are not of interest here. The sampling time was usually $5 \mathrm{~min}$ in order to ensure to be in steady state). The cold trap was subsequently removed from the setup and washed with dichloromethane $(25 \mathrm{~mL})$. Samples were analyzed off-line by gas chromatography. The sixteen 
EPA-PAHs were quantified by mass spectrometry (MS). All technical detail of these analyzes can be found in Bensabath'PhD [38]. Uncertainties appear with this analysis method because of the different steps between sampling and analysis, for example solvent may be lost by evaporation. To control for these effects, reproducibility experiments were performed.

All experiments were carried out at $1173 \mathrm{~K}$ and $8 \mathrm{kPa}$. The feed consisted of pure acetylene. Each experiment was performed two to four times to test reproducibility. In the presentation of the results, an average was calculated for each case and the range between the lowest and the highest values is represented by error bars.

In order to ensure the temperature uniformity in the reactor, measurements have been carried out to determine the reactor temperature (skin temperature in the sphere close to the nozzles). The K type thermocouple technology is used because its accuracy at high temperatures close to $1173 \mathrm{~K}$ is better than a Pt100. The sensor is connected to the Alhborn ${ }^{\circledR}$ precision measuring instrument. The gap between the set point temperature around $1173 \mathrm{~K}$ and the reactor (sphere and two pipes) is below $1 \%$ thanks to two other electrical resistances placed on both ends of the furnace to prevent heat losses. Therefore calculations and experiments supposed that on the one hand the JSR is isotherm and the other hand, that its temperature is equal to the set point temperature of the furnace.

Furthermore, short residence times were studied to avoid too much soot formation in the reactor. Moreover, the reactor was cleaned between two experiments by oxidation of carbon at $1173 \mathrm{~K}$ with an air inlet into the reactor to avoid the modification of reaction pathways of next experiment. These precautions limit the soot formation and the obstruction of pipes.

\section{Results and discussion}

\subsection{Experimental results and kinetic model}

Experimental results (Figure 8) were obtained in gas carburizing conditions, i.e., at low-pressure and high temperature, using pure acetylene. They were compared to results obtained from a detailed 
kinetic model [26]. This model was developed to describe formation of PAHs such as benzo[a]benzene during pyrolysis with light hydrocarbons (acetylene, ethylene, propane, etc.) in the same conditions. It was validated using experimental data from the literature [27]. Graphs showing mass fractions plotted as a function of the ideal residence time (Eq. 12) for the 16 EPA-PAHs ${ }^{1}$ were produced. The error bars on the experimental data points correspond to the experimental accuracy of GS-MS and represent the different errors during sample preparation. The PAHs produced in the greatest quantities were the lightest PAHs: naphthalene (fraction around $410^{-2}$ ) and acenaphthylene (fraction around $10^{-2}$ ). For PAHs like fluorene, phenanthrene, fluoranthene, I[1,2,3-cd]P, DB[a,h]A and pyrene the mass fractions was close to $10^{-3}$. For heavier PAHs, lower mass fractions were produced (fraction around $10^{-4}$ ). The $\mathrm{B}[\mathrm{a}] \mathrm{P}$ concentration was significant as it exceeded that of $\mathrm{B}[\mathrm{a}] \mathrm{A}$, chrysene, $\mathrm{B}[\mathrm{b}] \mathrm{F}$ and $\mathrm{B}[\mathrm{k}] \mathrm{F}$, which are lighter species. From data shown in Figure 8 we note that almost all PAH concentrations decreased when the residence time increased (except for naphthalene, the lightest). However, acetylene conversion increases with residence time [38]. On the one hand, this evolution can be explained by the large conversion of PAHs into heavier species which were not analyzed during this study. These species can be present as soot, or tar produced at a high rate of acetylene conversion and which deposit on the reactor walls and in downstream of the pyrolysis process. Generation of heavy compounds has also been observed in industrial carburizing [4]. On the other hand, the decrease in the amount of PAH formed when the residence time increases may be due to loss of PAHs by adsorption on soot, which was not all recovered for analysis [39-41]. When comparing experimental and modeled data, it emerged that PAH concentrations are inaccurately estimated by the model. Although the order of magnitude is correct and results are similar to experimental points, the model does not reproduce the trend for decreasing PAH concentrations as the residence time increases. This difference is due to higher conversion in these conditions. Many experiments performed in tubular reactors using lower acetylene conversion

\footnotetext{
${ }^{1} \mathrm{I}[1,2,3-\mathrm{cd}] \mathrm{P}$ and DB[a,h]A cannot be quantified separately, so they are considered together.
} 
showed good agreement between experimental and modeled data, and the same evolution when conversion increased [38].
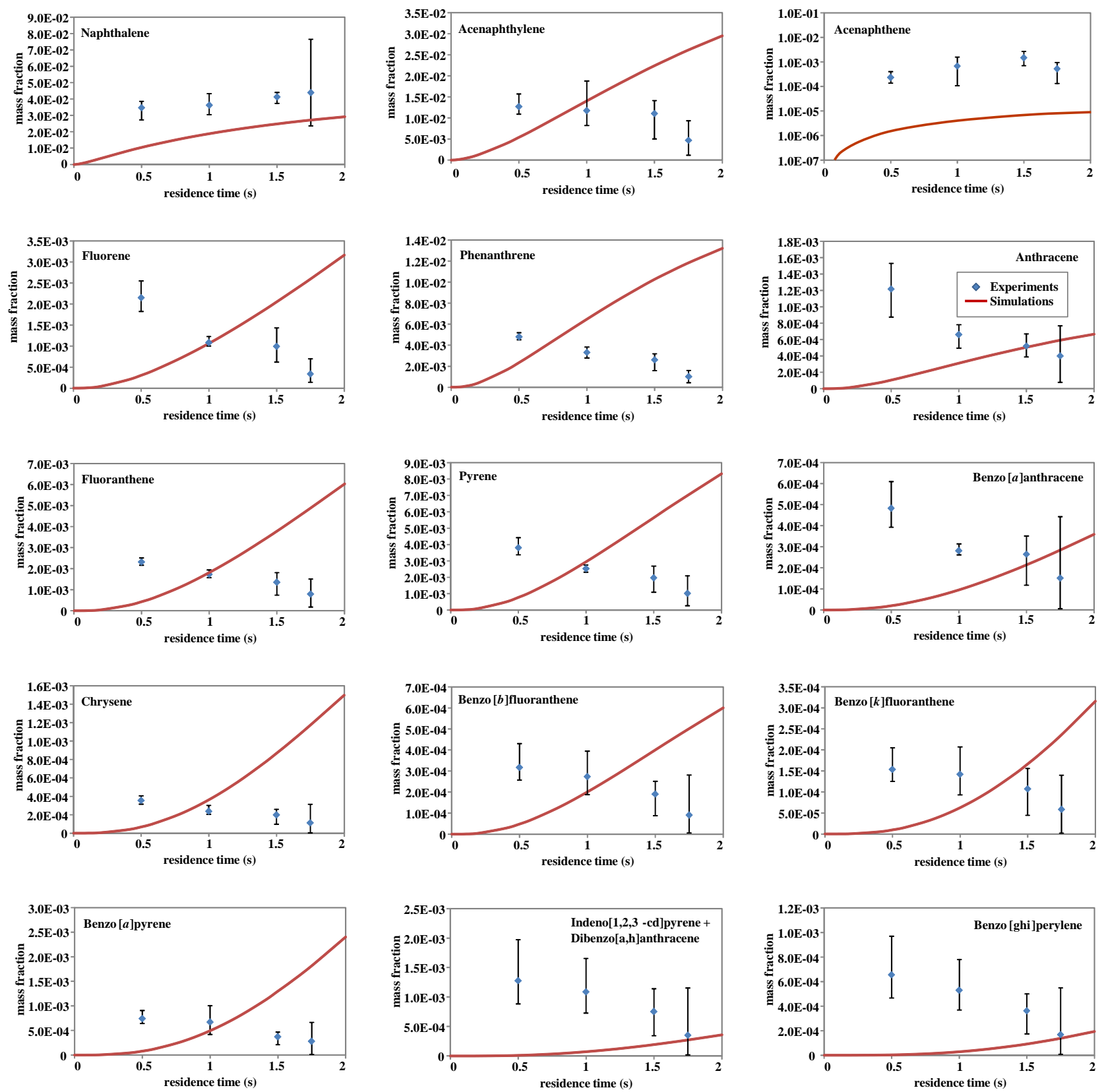

Figure 8: Mass fraction profiles for 16 EPA-PAHs produced during the carburizing process with pure acetylene - Comparison between experimental data and simulations $(\diamond$ experiments,

$$
\text { simulations) [12] - } \mathrm{T}=1173 \mathrm{~K}, \mathrm{P}=8 \mathrm{kPa}
$$

However, in the JSR, a proportion of the PAHs analyzed is consumed to form heavier species, such as soot, which is not considered in the model $[42,43]$. Therefore the order of magnitude of the PAHs 
calculated by the kinetic model might be overestimated. Otherwise some PAHs adsorbed onto soot deposited on the walls of the reactor were not analyzed. Nevertheless, the published kinetic model uses hydrodynamic assumptions such as plug flow or perfectly stirred reactor depending in the reactor used [26,44]. In our case, the JSR is assumed to be perfectly stirred. However, this may not be the case. Therefore, the RTDs determined by CFD may help to explain the difference between modeled and experimental data by quantifying parameters different than soot formation.

\subsection{Residence Time Distribution}

Figure 9 shows the results obtained when using a pulse signal to characterize the sphere and its four nozzles alone. The normalized RTD, $\mathrm{E}(\mathrm{t}, \tau)$, is presented as a function of the normalized time with respect to the residence time, $\mathrm{t} / \tau$. $\mathrm{E}(\mathrm{t}, \tau)$ was calculated by CFD simulation and using the ideal reactor relationship. The residence time which fits the ideal curve to the CFD simulation and some parameters characterizing the deviation from the ideal $\left(\mathrm{r}_{\tau}, \mathrm{r}_{\text {short-cicuit, }} \mathrm{r}_{\text {partial mix. }}\right)$ are indicated on each curve. Four operating conditions were investigated. Configuration 1 corresponded to ambient temperature and atmospheric pressure; a theoretical residence time of $1.00 \mathrm{~s}$ (Eq.12) was used. The CFD simulations in this study are confirmed to be correct. Indeed, our JSR is assumed to show good mixing at $300 \mathrm{~K}$ and $101.3 \mathrm{kPa}[10,28]$. This result confirms the advantages of this JSR (Figure 9 - Config. 1). The difference between the CFD-calculated residence time and the ideal residence time is null, and mixing is quasi-perfect, with only $2 \%$ short-circuit and $3 \%$ partial mixing. Our JSR can therefore be assumed to be perfectly mixed at $300 \mathrm{~K}$ and $101.3 \mathrm{kPa}$.

Few studies have investigated the hydrodynamic behavior of this JSR at high temperatures even though it has been widely used for combustion reactions by several groups $[19,45,46]$. Configuration 2 shows the RTD at $1073 \mathrm{~K}$ and $101.3 \mathrm{kPa}$, with an ideal residence time of $1 \mathrm{~s}$. Once again, perfect agreement between the CFD calculations and the ideal model was observed with no deviation. 
Configuration 3 corresponded to carburizing operating conditions under vacuum at $1073 \mathrm{~K}$ and $8 \mathrm{kPa}$. The inlet velocity and the volume flow rate remained unchanged. Thus, the ideal residence time should be equal to $1 \mathrm{~s}$. However, the residence time determined by CFD was close to $0.75 \mathrm{~s}$ and despite fitting, the CFD RTD curve failed to match the ideal curve. A $13 \%$ difference between the two residence times was calculated, and the CFD RTD curve deviates from the ideal. This deviation may be explained by the presence of a fraction of volume where mixing is only partial (41\%) and a proportion of the feed which goes directly to the outlet of the reactor without being mixed (6\%).
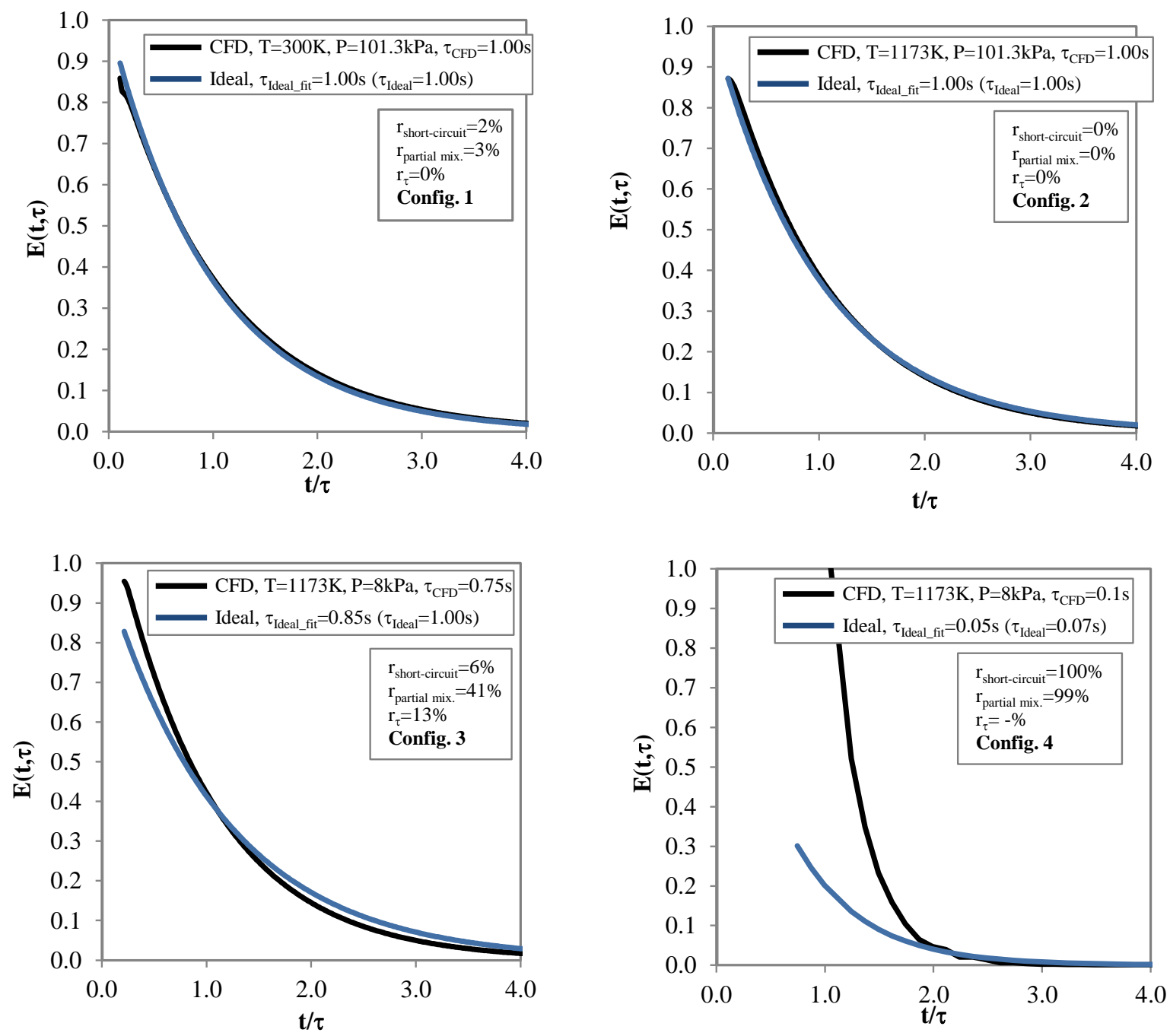

Figure 9: Normalized RTD based on CFD calculation of $\mathrm{E}(\mathrm{t}, \tau)$ plotted as a function of the normalized time $(t / \tau)$ for four different operating conditions - the stimulus is a pulse signal - 
deviation from ideal mixing, , $r_{\tau}$ (Eq. 6: $r_{\tau}=|\Delta \tau / \bar{\tau}|$ ), fraction of partial mixing, and the fraction of short-circuit were calculated as described [36]

In these pressure and temperature conditions, the mass flow rate is lower than in configurations 1 and 2 (Table 1). As the distance between molecules is higher under vacuum than under atmospheric pressure because the gas is expanded, the mean free path for the molecules is increased and more time is required to cover this path. In addition, gas diffusivity increases at decreasing pressure and increasing temperature. This phenomenon improves mixing, but appears negligible compared to the inertial force. A CFD study suggests that this kind of JSR can be used to investigate combustion kinetics if the mixing level is close to ideal [14]. This deviation from the ideal could explain the differences between experimental data and the kinetic model (Figure 8).

Furthermore, Authors explained that the mixing level increases when the residence time decreases [14]. Indeed, our pyrolysis experiments carried out under vacuum and at high temperature indicate a residence time between $0.5 \mathrm{~s}$ and $1.75 \mathrm{~s}$ (Table 1). Mixing is illustrated in Figures 10 and 11 obtained from CFD calculations, which show velocity contours and velocity streamlines. They confirm the increasing of mixing when the residence time decreases. For a majority of compounds this observation could result in better agreement between experimental data and the kinetic model (Figure 8) at short residence times $(0.5 \mathrm{~s})$ than at $1.75 \mathrm{~s}$. It is also preferable to work at low residence time to study the formation of PAHs during vacuum acetylene pyrolysis. 


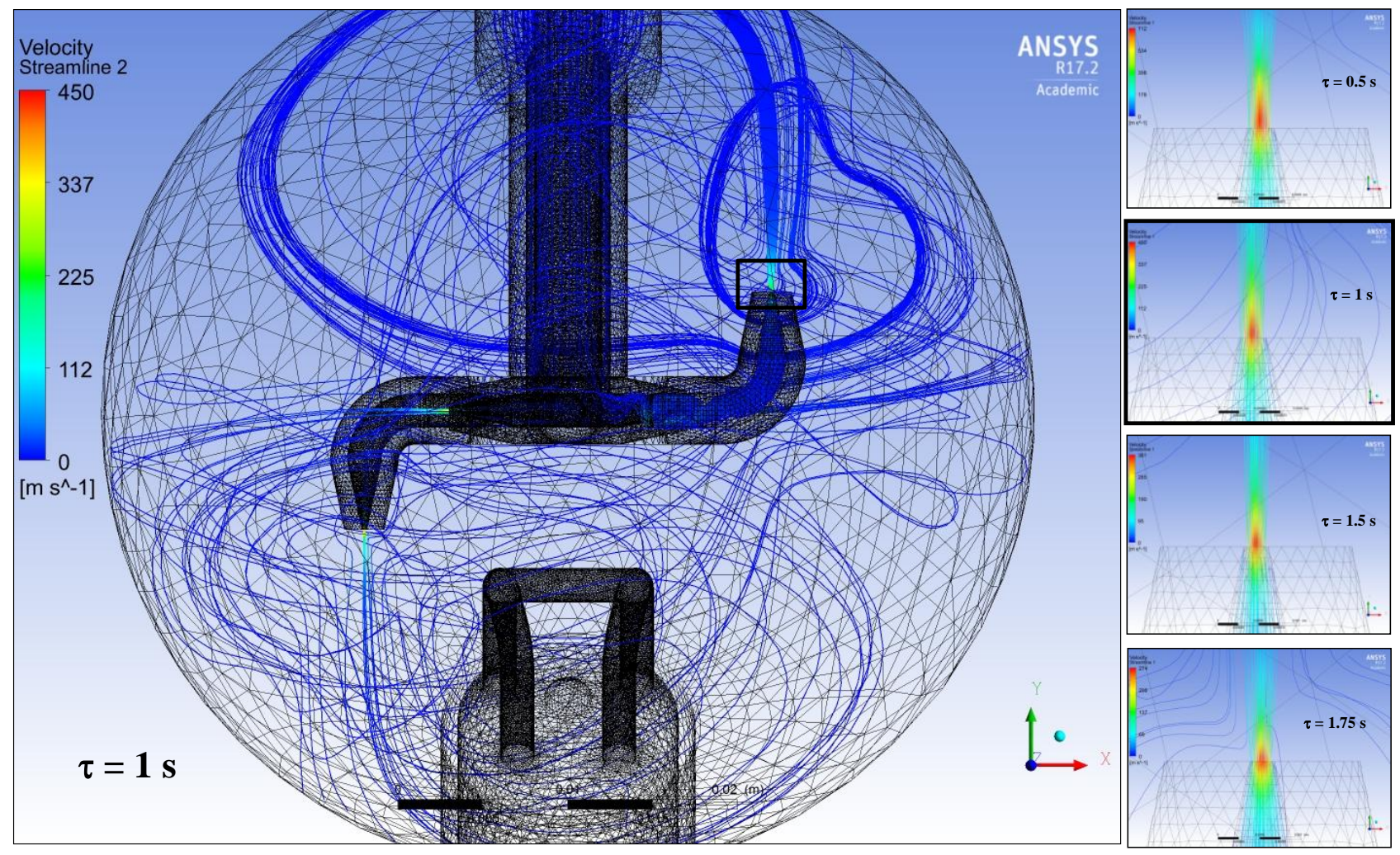

Figure 10: Velocity streamline within the sphere and nozzle zooms for residence times (Table 1) with the order of magnitude of local velocity both upstream and downstream of the inlet nozzle fine mesh used $-\mathrm{T}=1173 \mathrm{~K}, \mathrm{P}=8 \mathrm{kPa}$
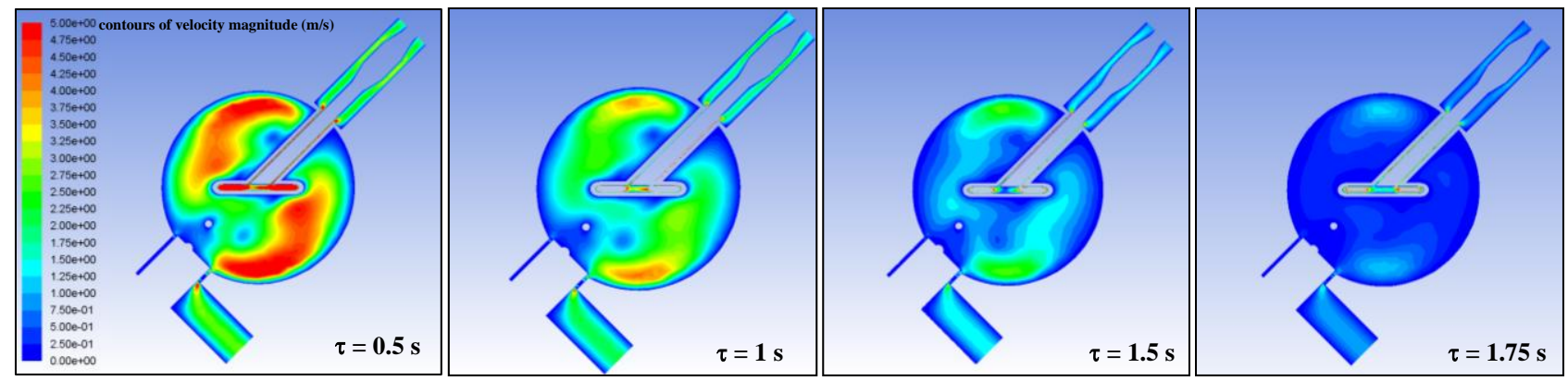

Figure 11: Contours of velocity magnitude for a range between 0 and $5 \mathrm{~m} / \mathrm{s}$ - four residence times $(0.5 ; 1 ; 1.5$ and $1.75 \mathrm{~s})$ for hydrodynamic flow at $1173 \mathrm{~K}$ and $8 \mathrm{kPa}$ carried out-CFD calculation performed by Ansys Fluent ${ }^{\circledR}$ software

However, if the Reynolds number of the four jets from the nozzles must be turbulent to achieve a perfect mixing the gas velocity at the nozzle's outlet must remain lower than the speed of sound to avoid irreversible damage to the quartz reactor $[10,21,47]$. In addition, using a high velocity would lead to further short-circuits and partial mixing. These problems are demonstrated with 
configuration 4 (Figure 9) where the inlet velocity was too high $\left(u_{\text {nozzle }}>c_{\text {sound }}\right)$. The ideal residence time in this configuration was close to $0.02 \mathrm{~s}$, whereas the residence time obtained by CFD simulation was equal to $0.1 \mathrm{~s}$. The ideal mixing model cannot fit the CFD calculation because the whole feed crosses the sphere to the outlet producing a short-circuit "channel" $\left(\mathrm{r}_{\text {short-circuit }}=100 \%\right)$ and no mixing $\left(\mathrm{r}_{\text {partial mix. }}=100 \%\right)$.

To characterize the influence of the two annular pipes and to show the influence of the residence time on hydrodynamic behavior, RTD was determined using a pulse stimulus at $8 \mathrm{kPa}$ and $1173 \mathrm{~K}$. Figure 12 shows the $\mathrm{F}$ function determined by CFD simulation and using the ideal reactor relationship as a function of time normalized with respect to the ideal residence time, $t / \tau$. The residence time which fits the ideal curve to CFD simulation and the deviation from the ideal, $\mathbf{r}_{\tau}(\%)$, are indicated on each RTD studied. The numerical RTD for the gas shows a certain deviation from the ideal reactor scenario. This result demonstrates that the behavior of our JSR is not close to a continuous stirred-tank reactor. Indeed, the $r_{\tau}$ calculated (Figure $12-$ Eq. 6) is between $75 \%$ and $35 \%$ and it decreases when the residence time increases. The differences between curves stem from the two pipes located on either side of the sphere (Figures 1 and 2). The proportion of time spent in the sphere is independent of the residence time, and its value is always equal to $74 \%$ (Table 1 ). Thus, during $26 \%$ of the total residence time, the fluid crosses two parts of the reactor displaying plug flow behavior (the annular space of the pipe can be assumed to display plug flow behavior). The first reason for this deviation from the ideal comes from the non-perfect stirring of the overall volume.

Furthermore, it is interesting to note that the CFD simulations perfectly fit the ideal case beyond $\tau_{\text {Ideal }}=7 \mathrm{~s}$, but not for shorter residence times. The two curves look similar, but they cross. The shape of the RTD is also different. The hydrodynamic behavior in the sphere depends to the gas velocity at the inlet nozzles [10]. However, the gas velocity may be too high (short residence time), causing short-circuits or partial volume mixing to appear in the sphere. Therefore, when studying 
pyrolysis reactions, the hydrodynamic behavior of the reactor according to the kinetic model should be taken into account to provide explanations on the evolution of PAH concentration during pyrolysis reactions. 

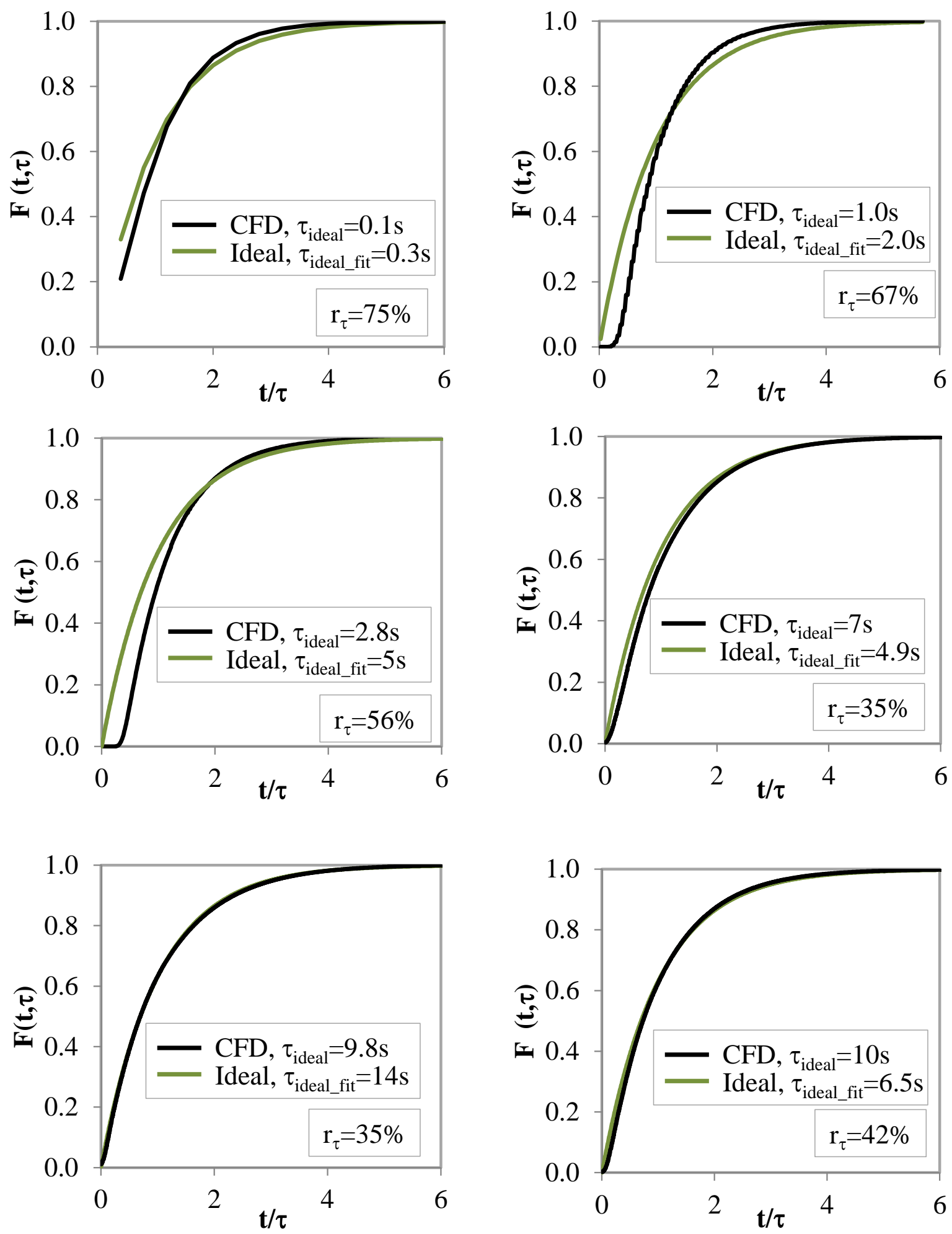

Figure 12: RTD CFD calculation and fit of ideal model: the stimulus was a stimulus signal $\left.\mathrm{P}=8 \mathrm{kPa}-\mathrm{T}=900{ }^{\circ} \mathrm{C}-0.1<\tau<10 \mathrm{~s}-\mathrm{Eq} .6: r_{\tau}=|\Delta \tau / \bar{\tau}|\right)$, 


\section{Conclusions}

In this study, hydrocarbon pyrolysis experiments were carried out in conditions close to lowpressure gas carburizing processes, at $1173 \mathrm{~K}, 8 \mathrm{kPa}$ and using pure acetylene to study the formation of the sixteen EPA-PAHs. They were performed in a quartz continuous JSR which is commonly assumed to be perfectly stirred [10]. The influence of residence time (between 0.5 and $1.75 \mathrm{~s})$ on the amount of PAHs generated was investigated. A kinetic model developed using Chemkin $^{\circledR}$ software was applied to simulate these experiments [20,26]. CFD simulations performed with Fluent ${ }^{\circledR}$ characterized the hydrodynamic flow of the gas phase through the JSR. RTD was determined using pulse and step stimulus. The aim was to determine whether the assumption of perfect stirring used in the Chemkin ${ }^{\circledR}$ model of the pyrolysis reaction was appropriate.

The orders of magnitude of PAHs produced were broadly correct based on comparison between model and experimental data. However, some differences were observed which depend on various experimental parameters used and assumptions made, including:

- any PAH which adsorbed onto soot deposited on the walls of the reactor was not analyzed.

- the formation of soot was not taken into account in the kinetic model or in experiments with long residence times. When residence time increased, some PAH converts into soot. The kinetic model does not continue its calculation following PAH formation, as a result the modeled PAH concentration increased with the residence time. However, experimentally, the PAH concentration was found to decrease with increasing residence time as heavy species converted into soot.

- differences between the hydrodynamic conditions in experimental reactors and the perfectly stirred reactor model. Indeed, several RTDs indicated that the JSR cannot be represented by the ideal stirred reactor model alone. In specific cases, the CFD simulations show too much turbulence within the reactor. Of course, turbulence is needed to achieve good mixing, but beyond a certain level, short-circuits and partial mixing volumes emerge due to the overly rapid gas velocity. 
- the hydrodynamic behavior varied as a function of the pressure. Indeed, even though several published studies explain how to choose reactor geometries when investigating combustion reactions, there is little research that assesses their effectiveness under vacuum $(8 \mathrm{kPa})$.

The assumptions made on the hydrodynamic characteristics of the reactor partially explain the differences between experimental and theoretical data. In the future, the kinetic model (perhaps simplified) will be included in the CFD code and other aspects will be studied using CFD such as:

- the influence of the geometry of the process furnace on PAH generation,

- the influence of pressure and temperature on JSR design.

Further experiments have to be planned, with an iron piece placed into the reactor to study the carburizing process. The aim is to investigate the influence of surface reactions $\mathrm{gas} / \mathrm{Fe}$ on the generation of gaseous compounds. These experiments may be carried out with the TAP because this reactor is small, easy to use with powder and the technique is fast and transient [6-7]. 


\section{References}

[1] H. Iwata, Advanced acetylene vacuum carburizing, IHI Eng. Rev., 38 (2005) 83-88.

[2] B. Yan, P. Xu, C.Y. Guo, Y. Jin, Y. Cheng, Experimental study on coal pyrolysis to acetylene in thermal plasma reactors, Chemical Engineering Journal, 207-208 (2012) 109-116.

doi.org/10.1016/j.cej.2012.05.111

[3] IARC-Monography, Monographs on Chemical agents and related occupations - A review of human carcinogens, 100F, 2012.

[4] C. Champmartin, F. Jeandel, H. Monnier, Maintenance of low-pressure carburizing furnaces: a source of PAH exposure, Ann. Work Expo. Health. 61 (2017) 321-332. https://doi.org/10.1093/annweh/wxw024.

[5] S. A Theofanidis, V. V., Galvita, H. Poelman, R. Batchu, L. C. Buelens, C. Detavernier, G. B. Marin, Mechanism of carbon deposits removal from supported Ni catalysts, Applied Catalysis B: Environmental, 239 (2018) 502-512. doi.org/10.1016/j.apcatb.2018.08.042

[6] J. T. Gleaves., J. R. Ebner, T. C. Kuechler, Temporal Analysis of Products (TAP)—A Unique Catalyst Evaluation System with Submillisecond Time Resolution, Catalysis Reviews, 30 (1) (1988) 49-116. doi:10.1080/01614948808078616

[7] J.T. Gleaves, G.S. Yablonsky, X. Zheng, R. Fushimi, P. L. Mills, Temporal analysis of products (TAP) - Recent advances in technology for kinetic analysis of multi-component catalysts, Journal of Molecular Catalysis A: Chemical, $315 \quad$ (2) $\quad$ (2010) 108-134. doi.org/10.1016/j.molcata.2009.06.017

[8] M. Djokic, H-H. Carstensen, K. M. Van Geem, G. B. Marin, The thermal decomposition of 2,5dimethylfuran, Proceedings of the Combustion Institute, 34 (2013) 251-258. doi.org/10.1016/j.proci.2012.05.066 
[9] M.R. Harper, K. M. Van Geem, S.P. Pyl, G. B. Marin, W.H., Green, Comprehensive reaction mechanism for n-butanol pyrolysis and combustion, Combustion and Flame, 158 (1) (2011) 16-41. doi.org/10.1016/j.combustflame.2010.06.002

[10] D. Matras, J. Villermaux, Un réacteur continu parfaitement agité par jets gazeux pour l'étude cinétique de réactions chimiques rapides, Chemical Engineering Science 28 (1) (1973) 129-137.

[11] F.H. Vermeire, H.-H. Carstensen, O. Herbinet, F. Battin-Leclerc, G. B. Marin, K. M.Van Geem, Experimental and modeling study of the pyrolysis and combustion of dimethoxymethane, Combustion and Flame, 190 (2018) 270-283. doi.org/10.1016/j.combustflame.2017.12.001

[12] F.H., Vermeire, H.-H. Carstensen, O. Herbinet, F. Battin-Leclerc, G. B. Marin, K. M.; Van Geem, The thermal decomposition of furfural: molecular chemistry unraveled. Proceedings of the Combustion Institute. In Press, Corrected Proof. https://doi.org/10.1016/j.proci.2018.05.119

[13] O. Herbinet, F. Battin-Leclerc, Progress in understanding low-temperature organic Compound Oxidation Using A Jet-Stirred Reactor, Int. Journal Chem. Kinet., 46(10) (2014), 619-639 Doi 10.1002/Kin.20871

[14] I. Gil, and P. Mocek, CFD analysis of mixing intensity in jet stirred reactors, Chemical and Process Engineering, 33 (3) (2012) 397-410. doi: 10.2478/v10176-012-0035-9.

[15] P.M. Marquaire, G.M. Côme, Non quasi-stationary state pyrolysis. Induction period of neopentane pyrolysis, Reaction Kinetics and Catalysis Letters, 9 (2) (1978) 165-169.

[16] P. Dagaut, M. Cathonnet, J.-C. Boettner, Kinetic modeling of propane oxidation and pyrolysis International Journal of Chemical Kinetics, 24 (9) (1992) 813-837.

[17] M. Nowakowska, O. Herbinet, A. Dufour, P.A. Glaude, Detailed kinetic study of anisole pyrolysis and oxidation to understand tar formation during biomass combustion and gasification, Combustion and Flame, 161 (6) (2014) 1474-1488.

[18] A. E. Muñoz Gandarillas, K. M. Van Geem, M. Reyniers, G. B. Marin, Influence of the reactor material composition on coke formation during ethane steam cracking, Industrial and Engineering Chemistry Research, 53 (15) (2014) 6358-6371. 
[19] O. Herbinet, P-M. Marquaire, F. Battin-Leclerc, et al., Thermal decomposition of n-dodecane: Experiments and kinetic modeling, Journal Anal Appl Pyrol.,78 (2007) 419-429.

[20] Chemkin ${ }^{\circledR}$ theory manual, rapport CK-THE-15151-1601-UG-1, Ansys ${ }^{\circledR}$ Company (2016).

[21] O. Herbinet, G. Dayma, Jet-Stirred Reactors, in Battin-Leclerc, F., Simmie, J.M., and Blurock E., Cleaner Combustion: Developing Detailed Chemical Kinetic Models, Springer (2013) 183-210, Green Energy and Technology 978-1-4471-5306-1 <10.1007/978-1-4471-5307-8>. https://hal.archives-ouvertes.fr/hal-00880195.

[22] W.W Ayass, E.F. Nasir, F. A. Farooq, S.M. Sarathy, Mixing-structure relationship in jet-stirred reactors, Chemical Engineering Research and Design, 111 (2016) 461-464. doi: 10.1016/j.cherd.2016.05.016

[23] W. Wibel, A. Wenka, J.J. Brandner, R. Dittmeyer, Measuring and modeling the residence time distribution of gas flows in multichannel microreactors, Chemical Engineering Journal, 215-216, (2013) 449-460. doi.org/10.1016/j.cej.2012.10.011.

[24] C. Casado, J. Marugán, R. Timmers, M. Muñoz, R. van Grieken, Comprehensive multiphysics modeling of photocatalytic processes by computational fluid dynamics based on intrinsic kinetic parameters determined in a differential photoreactor, Chemical Engineering Journal, 310, Part 2, 15 (2017) 368-380. doi.org/10.1016/j.cej.2016.07.081

[25] ANSYS Fluent Getting Started Guide Release 18.0 January 2017, ANSYS, Inc. and ANSYS Europe, Ltd. are UL registered ISO 9001: 2008 companies.

[26] T. Bensabath, H. Monnier, P-A. Glaude, Detailed kinetic modeling of the formation of toxic Polycyclic Aromatic Hydrocarbons (PAHs) coming from pyrolysis in low-pressure gas carburizing conditions. Journal of Analytical and Applied Pyrolysis, 122 (2016) 342-354. doi.org/10.1016/j.jaap.2016.09.007. 
[27] K. Norinaga, O. Deutschmann, K.J Hüttinger, Analysis of gas phase compounds in chemical vapor deposition of carbon from light hydrocarbons, Carbon, 44 (9) (2006) 1790-1800. https://doi.org/10.1016/j.carbon.2005.12.050.

[28] P. Azay, G.M. Côme, Temperature gradients in a continuous flow stirred tank reactor, Ind Eng Chem Process Des Dev 18 (1979) 754-756.

[29] R. David, D. Matras, Règles de construction et d'extrapolation des réacteurs auto-agités par jets gazeux, The Canadian Journal of Chem. Eng. 53 (1975) 297-300.

[30] P. Danckwerts, Continuous flow systems. Distribution of residence times, Chemical Engineering Science, 2, 1 (1953) 1-13.

[31] O. Levenspiel, Chemical Reaction Engineering, John Wiley \& Sons. ISBN 0-471-25424-X. (1999)

[32] S. Patankar, Numerical heat transfer and fluid flow, by CRC Press Textbook 1980. ISBN 9780891165224 - CAT\# RT5223.

[33] V. Yakhot, S.A. Orszag, S. Thangam, T.B. Gatski, C.G. Speziale, Development of turbulence models for shear flows by a double expansion technique, Physics of Fluids A. 4 (7) (1992) 15101520. doi.org/10.1063/1.858424.

[34] D. J. Van Cauwenberge, C. M. Schietekat, J. Floré, K. M Van Geem, \& , G. B. Marin, CFDbased design of 3D pyrolysis reactors: RANS vs. LES, Chemical Engineering Journal, 282 (2015) 66-76. doi:10.1016/j.cej.2015.03.020

[35] R.B. Bird, W.E. Stewart, E.N. Lightfoot, Transport. Phenomena, Chemical Engineering Department, University of Wisconsin-Madison, John Wiley \& Sons, Inc. New York (1960).

[36] A. Cholette, L. Cloutier, Mixing efficiency determinations for continuous flow systems, The Canadian Journal of Chemical Engineering, 37, 3 (1959) 105-112.

[37] N.E. Bruce, Residence Time Theory, Industrial \& Engineering Chemistry Research, 47, 10 (2008) 3752-3766. doi:10.1021/ie071635a. 
[38] T. Bensabath, Approche préventive pour une réduction des Hydrocarbures Aromatiques Polycycliques (HAP) dans les fours à pyrolyse - Application à la cémentation gazeuse à basse pression, Thesis Lorraine University France (2017). https://tel.archives-ouvertes.fr/tel-01710271.

[39] Y. Cheng, T. Li, C. Rehmet, H. An, B. Yan, Y. Cheng, Detailed kinetic modeling of chemical quenching processes of acetylene-rich gas at high temperature, Chemical Engineering Journal. 315, (2017) 324-334. doi.org/10.1016/j.cej.2017.01.040

[40] K. Ono, M. Yanaka, S. Tanaka, Y. Saito, H. Aoki, O. Fukuda, T. Aoki, T. Yamaguchi, Influence of furnace temperature and residence time on configurations of carbon black, Chemical Engineering Journal, 200-202 (2012) 541-548. doi.org/10.1016/j.cej.2012.06.061

[41] K. Ono, M. Yanaka, Y. Saito, H. Aoki, O. Fukuda, T. Aoki, T. Yamaguchi, Effect of benzeneacetylene compositions on carbon black configurations produced by benzene pyrolysis, Chemical Engineering Journal. 215-216 (2013) 128-135. doi.org/10.1016/j.cej.2012.10.085

[42] K. Ono, A. Watanabe, K. Dewa, Y. Matsukawa, Y. Saito, Y. Matsushita, H. Aoki, O. Fukuda, T. Aoki, T. Yamaguchi, Detailed kinetic analysis of the effect of benzene-acetylene composition on the configuration of carbon nanoparticles, Chemical Engineering Journal, 250 (2014) 66-75. doi.org/10.1016/j.cej.2014.03.091

[43] K. Norinaga, Y. Sakurai, R. Sato, J-I. Hayashi, Numerical simulation of thermal conversion of aromatic hydrocarbons in the presence of hydrogen and steam using a detailed chemical kinetic model, Chemical Engineering Journal, 178 (2011) 282-290. doi.org/10.1016/j.cej.2011.10.003 [44] K. Norinaga, O. Deutschmann, N. Saegusa, J-I. Hayashi, Analysis of pyrolysis products from light hydrocarbons and kinetic modeling for growth of polycyclic aromatic hydrocarbons with detailed chemistry, Journal of Analytical and Applied Pyrolysis, 86 (1) (2009) 148-160. https://doi.org/10.1016/j.jaap.2009.05.001.

[45] W. Bartok, C. E. Heath, M.A. Weiss, Mixing in a jet-stirred reactor. AIChE Journal, 6 (1960) 4, 685-687. 
[46] P. Dagaut, M. Cathonnet, J.P. Rouan, et al.. A jet-stirred reactor for kinetic studies of homogeneous gas-phase reactions at pressures up to ten atmospheres ( 1 MPa), Journal Phys. E:

Sci. Instrum., 19, (1986)207-209.

[47] J.O. Hinze, B.G. Van Der Hegge Zijnen, Transfer of heat and matter in the turbulent mixing zone of an axially symmetrical jet, Appl. Sci. Res. A1 (1949) 435-461.

\section{Supplementary data - Thresholds for PAH detection by GC-MS (based on $120 \mathrm{~mL}$ per} sample)

\begin{tabular}{|c|c|}
\hline PAH & Threshold ( $\mu$ g per sample) \\
\hline Naphthalene & 1.5 \\
\hline Acenaphthylene & 0.5 \\
\hline Acenaphthene & 1 \\
\hline Fluorene & 0.1 \\
\hline Phenanthrene & 0.1 \\
\hline Anthracene & 0.1 \\
\hline Fluoranthene & 0.2 \\
\hline Pyrene & 0.2 \\
\hline $\mathrm{B}[a] \mathrm{A}$ & 0.1 \\
\hline Chrysene & 0.1 \\
\hline $\mathrm{B}[b] \mathrm{F}$ & 0.1 \\
\hline $\mathrm{B}[k] \mathrm{F}$ & 0.1 \\
\hline $\mathrm{B}[a] \mathrm{P}$ & 0.1 \\
\hline $\mathrm{I}[1,2,3-c d] \mathrm{P}+\mathrm{DB}[a, h] \mathrm{A}$ & 0.2 \\
\hline $\mathrm{B}[g h i] \mathrm{P}$ & 0.2 \\
\hline
\end{tabular}




\begin{tabular}{|c|c|c|}
\hline $\mathrm{C}(\mathrm{t})$ & tracer concentration measured at the reactor outlet & $(\mathrm{kg} / \mathrm{kg})$ \\
\hline $\mathrm{C}_{0}$ & tracer concentration introduced at the reactor inlet & $(\mathrm{kg} / \mathrm{kg})$ \\
\hline $\mathrm{c}_{\text {sound }}$ & speed of sound & $\mathrm{m} / \mathrm{s}$ \\
\hline $\mathrm{d}_{\text {nozzle }}$ & nozzle diameter in the JSR & $\mathrm{m}$ \\
\hline $\mathrm{E}$ & residence time distribution function & $(-)$ \\
\hline $\mathrm{F}$ & downstream signal & $(-)$ \\
\hline $\mathrm{k}$ & kinetic energy & $\mathbf{J}$ \\
\hline $\mathrm{m}$ & fraction of total volume which is perfectly mixed & $(-)$ \\
\hline $\mathrm{n}$ & fraction of the feed entering the zone of perfect mixing & $(-)$ \\
\hline $\mathrm{P}$ & pressure & $\mathrm{Pa}$ \\
\hline Q & volume flow rate from a nozzle outlet & $\mathrm{m}^{3} / \mathrm{s}$ \\
\hline $\mathrm{R}_{\text {sphere }}$ & radius of the sphere (JSR) & $\mathrm{m}$ \\
\hline$r_{\tau}$ & \multicolumn{2}{|c|}{ difference between two residence times: CFD calculation and perfectly stirred } \\
\hline$r_{\text {partial mix. }}$ & fraction of fluid which is partially mixed & $(-)$ \\
\hline$r_{\text {short-circuit }}$ & fraction of short-circuit & $(-)$ \\
\hline$S_{\text {nozzle }}$ & section of nozzle outlet & $\mathrm{m}^{2}$ \\
\hline $\mathrm{T}$ & temperature & $\mathrm{K}$ \\
\hline $\mathrm{t}$ & time & $\mathrm{s}$ \\
\hline$\tilde{u}, \mathrm{u}_{\mathrm{x}}, \mathrm{u}_{\mathrm{y}}, \mathrm{u}_{\mathrm{z}}$ & velocity of the gas & $\mathrm{m} / \mathrm{s}$ \\
\hline V & volume & $\mathrm{m}^{3}$ \\
\hline $\mathrm{x}, \mathrm{y}, \mathrm{z}$ & cartesian coordinate & $(-)$ \\
\hline$y^{+}$ & non-dimensional wall distance & $(-)$ \\
\hline $\bar{y}^{+}$ & non-dimensional average wall distance & $(-)$ \\
\hline
\end{tabular}

Greek letters 


$\begin{array}{llc}\mu & \text { dynamic viscosity of the gas } & \text { Pa.s } \\ \rho & \text { gas density } & \mathrm{kg} / \mathrm{m}^{3} \\ \tau & \text { residence time } & \mathrm{s} \\ \bar{\tau} & \text { arithmetic mean of } \tau_{C F D} \text { and } \tau_{\text {ideal } L_{-f i}} . & \mathrm{s} \\ \nabla & \text { gradient } & (-)\end{array}$

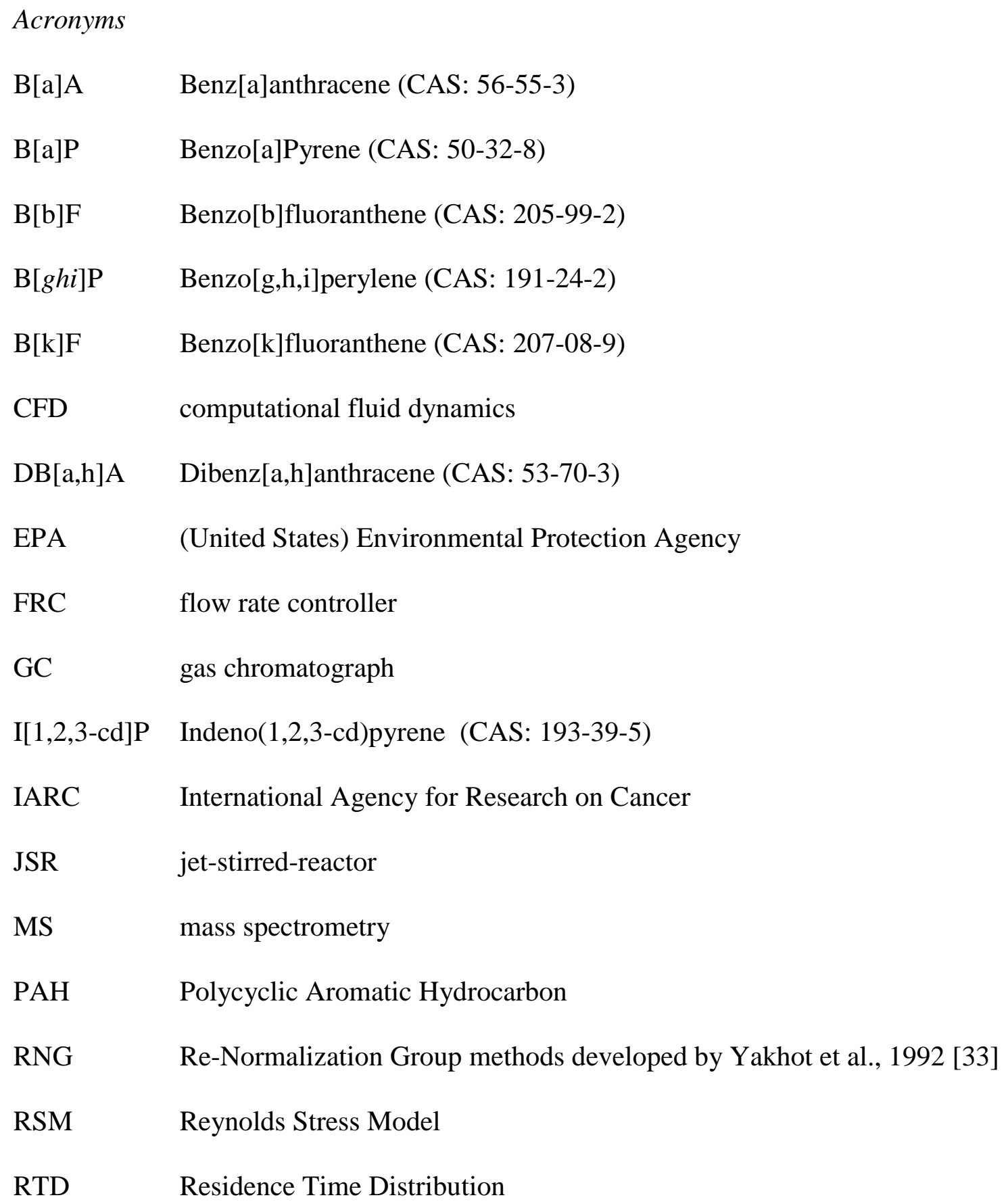


